\title{
BIM-BASED AUGMENTED REALITY TOOL FOR THE MONITORING OF CONSTRUCTION PERFORMANCE AND PROGRESS
}

\author{
Julia Ratajczak $^{1,2}$, Carmen Marcher ${ }^{3}$, Christoph Paul Schimanski ${ }^{3}$, Alice Schweigkofler ${ }^{3}$, \\ Michael Riedl ${ }^{3}$ and Dominik T. Matt ${ }^{2,3}$ \\ ${ }^{1}$ Free University of Bozen-Bolzano, Bolzano, Italy \\ ${ }^{2}$ Budimex SA, Warsaw, Poland \\ ${ }^{3}$ Fraunhofer Italia Research, Bolzano, Italy
}

\begin{abstract}
The construction industry is still lagging behind other industries in adopting new technologies for monitoring of performance and progress of construction works. In other industries like production or automotive such processes are already partly or fully automated. To improve effectiveness of construction scheduling and quality of works, this research proposes a BIMbased augmented reality application for site managers so-called AR4C. This application is combining Location-Based Management System and Building Information Modeling (BIM) to visualize in Augmented Reality key information related to progress and performance of construction works superimposed on the real world. This paper describes methodologies and technologies implemented in the AR4C application to control effectively construction works.
\end{abstract}

\section{Introduction}

The construction industry is a project-based industry characterized by heterogeneity, extreme complexity, fragmented supply chain and variability of trade performance. Construction projects are subjected to high risk in terms of schedule deviation due to inefficient processes and poor communication, which generate up to $30 \%$ of construction costs (The Economist, 15/01/2000). In addition, some unpredictable factors like weather conditions can extend the duration of certain construction tasks. Olawale \& Sun (2010) found that in UK, 60\% of construction project organizations struggle with time and cost overruns on more than $10 \%$ of their projects. According to statistics published by KPMG in 2015 on the global construction industry, only $25 \%$ of projects came within $10 \%$ of their original deadlines in the past three years. This occurs, because inadequate and inaccurate monitoring and control processes are practiced on worksites (Memon et al., 2012). An effective monitoring of construction performance and progress is crucial to deliver project on time within the established budget (Nassar, 2009). Continuous verification of project status allows site manager to identify problems early and make conscious decisions on time to prevent scheduling deviations (Maalek \& Sadeghpour, 2012). In conventional processes, monitoring and controlling of construction works is mostly done by manual and paper-based methods (Navon, 2007). It is time-consuming process, which requires that site managers analyze and calculate huge amount of data and fill paper forms. In addition, site managers often do not have at their disposal tools to visualize and represent the information in a simple and user-friendly manner (Lee, S., Pena-Mora, 2006).

To provide site mangers with meaningful data on project performance and progress, it is important to introduce efficient monitoring methods. It is possible to reduce execution schedule devotions up to $15 \%$ (IBC, 2000), project cost up to $10 \%$ (IBC, 1999) as well as cost of reworks, claims and disputes (Yates \& Epstein, 2006), if successful progress monitoring is applied. It is important to identify a management system that enables an efficient method to collect data on project progress and performance. A promising management system is a Location-based Management System (LBMS). Seppänen (2009) found that it is possible to achieve a duration compression of $10 \%$ with schedule optimization. Seppänen et al. (2014) evaluated that LBMS is able to increase production rate on average $37 \%$ and prevents production problems by $50 \%$. LBMS supports the effective allocation of resources and the reduction of waste, which are related to some lean construction principles (Andersson \& Christensen, 2007). LMBS requires a constant monitoring of productivity rates and resource distribution, since these factors are recognized as waste, if managed inefficiently (Kenley and Seppänen, 2010). Beyond scheduling monitoring, an important aspect of performance is the quality control of performed works. According to Mills et al. (2009) omissions in quality controls may cause construction errors and quality degradation, which negatively affect both costs and project schedule. Therefore, insufficient management and low quality control affects delays, project profitability, cost increase (Zavadskas et al., 2014) and it has relevant impacts on productivity (Yi \& Chan, 2014).

Once site managers dispose of information on project performance and progress, it is important to visualize and highlight the most important data. The representation of project status data can be done through a dashboard, which displays information on 
key performance indicators (KPIs). It can save time of site managers in reviewing reports and calculating data. Dashboard provides KPIs values according to predefined goals and shows at a glance the current project status. It provides a better understanding of the project, allows site managers to make fast decisions and corrective actions (Lamptey \& Fayek, 2012). Augmented Reality (AR) is promising technology to improve visualization of such information directly on the construction site. Kopsida \& Brilakis (2013) investigated the use of AR for project progress monitoring as a way to compare it to the as as-planned schedule.

\section{Background on systems for performance and progress monitoring}

The Information and Communication Technologies (ICT) utilization ratio in the construction industry is still relatively low (Dehlin \& Olofsson, 2008). McKinsey Global Institute Industry Digitization Index from 2015 (McKinsey Global Institute, 2016) classified the construction industry at the end of the list. It does not mean that the construction industry does not attempt to adopt new solution and technologies. Construction companies are willing to test new ICT solutions that can improve design and construction processes. Nevertheless, there are several barriers (organizational, technical, lack of skilled employees, social and habitual resistance to change, etc.) to fully implement ICT solutions and automate conventional processes. In recent years, the effort put in the adoption of ICT in the construction industry has had a significant impact on both productivity and economic growth of construction companies (Kenley \& Seppänen, 2010). Along with the development of technologies like Building Information Modeling (BIM), Augmented Reality (AR), Virtual Reality (VR) and Internet of Things (e.g. near-field communication (NFC) and radio-frequency identification (RFID) sensors), new hardware and software tools have been introduced to the construction industry, especially in the design and construction phase. These technologies allow the automation of construction processes and have potentiality to improve monitoring of construction works and manage information flow as well as reduce construction errors. Leading commercial software companies are proposing solutions for automating construction project control. BIM-based construction management platforms and mobile filed applications enable users to automate planning and monitoring of construction works, management of documents as well as information sharing on project status. Autodesk ${ }^{\circledR}$ BIM360 Docs ${ }^{\mathrm{TM}}$, Oracle Aconex Connected BIM, Oracle Latista, Tekla BIMsight, Dalux TwinBIM are some examples of them. These solutions use BIM model of the project to facilitate controlling process and integrate often Augmented Reality/Virtual Reality technology to access the most current project information through the 3D model. The 3D model is overlaid into the real perspective. Increasing automation of controlling processes on site, due to BIM and AR technology, can improve decision-making process, provide real-time access to information and report issues. Nevertheless, these applications do not support the monitoring of construction process and performance and do not manage construction process according to lean management practices. If consider applications that manage projects according to lean construction methods, such as Autodesk ${ }^{\circledR B I M} 360$ Plan $^{\mathrm{TM}}$, Trimble Vico Office, VisiLean, the use of AR technology to display $3 \mathrm{D}$ building model superimposed on the real world with all task related information and with construction progress and performance KPIs has not been integrated yet. VTT Technical Research Centre has been developing an AR implementation VisiLean to display $3 \mathrm{D}$ models in $\mathrm{AR}$, but it is an external applications. So, it emerges that the integration of AR to provide context-aware project and progress information related to construction works could be investigated for BIM and Lean Construction application.

Moreover, literature review shows that research projects have been carried out to provide visual information on project performance and progress. KanBIM is BIM-based system to support production planning and day-to-day production control on construction sites based on the Last Planner System. It provides visual information reported on building model (Sacks et al., 2013). D4 AR - a new imagebased modeling technique for visualizing progress discrepancies between as-planned and as-built is using daily progress photographs and superimposition of the reconstructed scene over as-planned 4D models (Golparvar-Fard et al., 2009). Golparvar-Fard et al. (2009) and Roh et al. (2009) have developed an augmented reality model that enables user to walk through the construction site and display progress status. Kopsida and Brilakis (2016) proposed a solution for markerless mobile-based augmented reality solution to assist inspection and progress monitoring for interior activities by displaying 3D asplanned BIM model and detecting differences with actual construction. In the ACCEPT project (Ratajczak et al., 2017), a system for construction management was developed, which uses smart glasses and smartphone to display in AR overlaid digital model and information onto real construction environment. However, in these research projects, the monitoring and controlling of project performance and progress according to lean construction method through AR has not be proposed.

\section{Proposed solution}

This research paper describes a BIM, AR and Leanbased mobile application, so-called AR4C, to support 
construction processes on site according to lean construction methods. AR4C aims to improve performance of the construction process by monitoring of construction works on a daily basis in a specific location of the project. The AR4C application is envisioned to enhance the project control by rapidly identification of deviations from project schedule, variation in performance and progress using AR combined with BIM and LBMS. The project controlling methodology applied to AR4C has initiated within the European project - ACCEPT (www.accept-project.com) funded by the Horizon 2020 Framework Programme and has been continued by Fraunhofer Italia and Free University of BozenBolzano in the Ph.D. research project, presented in this paper. In this research, the identified problem is related to the lack of field tools for site managers that use LBMS to monitor construction progress and performance.

The AR4C application addresses this problem and it is envisioned as a field tool mainly for site managers and workers to provide them with context-aware information at anytime and anywhere on the construction site. In this paper, the authors focus on performance and progress controlling that could be potentially done by using the AR4C application. More information on other functionalities of this application can be read in the previous research paper (Ratajczak et al., 2018). The AR4C application is a prototype version and it is developed for the Android smartphone Lenovo Phab 2 Pro, since it integrates Google Project Tango technology like motion tracking and depth perception. This technology gives the ability to detect the device position relative to the world around it with high precision and accuracy. These two features accuracy and precision are mandatory for displaying $3 \mathrm{D}$ model in AR, which is superimposed on the real world location. It is also important to underline that the authors established this research project to investigate benefits that could be reached by using BIM, AR and Lean application on site, but also define obstacles in implementing these technologies and lean methods in construction companies. Human factor plays an essential role in adopting new technologies/methods, so the user experience and acceptance will be evaluated as well.

\section{Methodologies and enabling technologies}

The AR4C application supports site managers in the controlling process of construction performance and progress. The main contribution of this research work was focused on the practical and theoretical integration of different technologies and methodologies into one system. The novelty of this integration consists in creating a unique field application that is able to detect easily scheduling deviation by visualizing construction progress in $\mathrm{AR}$, to provide daily progress and performance data of construction work as well as to provide context-aware information/documents on scheduled tasks. To enable these functionalities several methodologies and technologies have been implemented in AR4C. Their description and implementation is reported below.

\section{Building Information Modeling (BIM)}

$\mathrm{BIM}$ is a $3 \mathrm{D}$ model-based process of generating and managing building data (e.g. geometry, spatial relationships, quantities, proprieties of building components, etc.) during its life cycle. BIM is also a tool that facilitates more integrated design and construction process, which results in increased productivity and accuracy during the design and construction phase, better quality of buildings at lower cost and reduced project duration (Eastman et al. 2008). In AR4C, BIM is used to provide 3D interactive model that can provide geometrical and technical data on components and materials, and locations associated to each component/material by using specific codes. This information forms a reliable basis for monitoring of construction works and it is imported to AR4C using exchange file formats like .fbx and .xml.

\section{Lean construction methods}

Lean construction is a management approach based on principles of the Toyota Production System, which has been adopted to the construction context. It focuses on removing waste, creating value for the customer, and continuous improvement (Sacks et al., 2010). According to Kenley \& Seppänen (2010), LBMS can be considered as a lean technique, since it focuses on production control based on pull controlling. In LBMS, construction activities and their controlling refer always to locations. Organization of activities by locations provides more comprehensive information, avoids interruption between different trades, and enhances constancy of the workflow (Kenley \& Seppänen, 2010). It can also increase productivity and prevent production problems, which cause cascading delays and impact project durations by $10 \%$ (Seppänen, 2009).

In $\mathrm{AR} 4 \mathrm{C}$, task scheduling is defined according to location hierarchy level with respective codes, socalled LBS codes (Location Breakdown Structure). Codes can be defined based on three-level hierarchy (Figure 1). Each of the location hierarchy has a different scope. The highest level (level 1) refers to locations, where structure can be built independently (e.g. individual buildings or parts of large building). The middle level (level 2) should be defined to plan production flow of structures, so it refers always to floors. The lowest level (level 3) is used to plan effectively construction tasks at detailed level. It is important to define locations in a way to carry out accurate monitoring of task progress. In AR4C, LBS codes are composed by combining abbreviation of location nomenclature at each level, e.g. 
BLDG1.F1.U1: Building 1 - Floor 1 - Unit 1. Moreover, task hierarchy has been introduced in LMBS. Each construction task is defined by WBS code (Work breakdown Structure) and aforementioned LBS code. The combination of both codes provides a unique nomenclature for each task, so-called WBS/LBS code, which is used in the AR4C to identify a specific task in a specific location. By embedding these codes in 3D building model in proprieties and parameters of its elements/materials (as shown in Figure 1), the application is able to display information on performance and progress related to a specific location for selected tasks or group of tasks and highlight progress status of objects, which contain these codes.

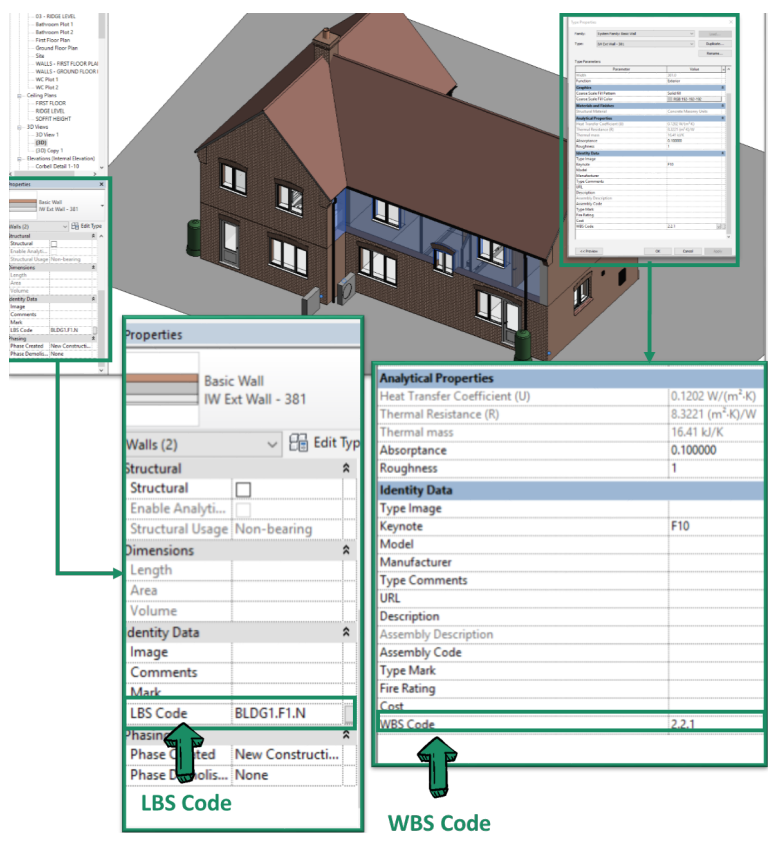

Figure 1 Codification of tasks and locations in BIM

\section{Tiered methodology}

The Tiered Structure (TS) methodology has been adopted to provide tailored KPIs on construction performance and progress to different stakeholders of the construction project. A message communicated by KPIs should yield information that is meaningful, timely, and reliable for a specific group of stakeholders in order to make conscious and rapid decisions. For this reason, TS methodology introduces four levels (tiers) of information granularity, which refer to project work breakdown structure and business owners of each level. This methodology is comprised of four tiers (Tier 0-3):

- Tier 0 represents high-level of project information - building level, where tailored information are delivered to the client and to the project manager.

- Tier 1 refers to construction work package level (e.g. structures) and are delivered to the project manager and site manager.
- Tier 2 is related to construction task level (e.g. concrete slab). The owner of this level is a site manager.

- Tier 3 represents the lowest level of the project information - workflow, which defines a sequence of construction activities (e.g. formworks, steal bar reinforcements, etc.) that should be performed by a crew to complete a task on tier 2 . This tier creates a foundation for the monitoring of the entire construction process of the project.

\section{Monitoring of construction performance and progress}

The concept of "pitching" (Dallasega et al., 2013) is used to apply LBMS and thus entails the opportunity to schedule and monitor location-based tasks on a daily basis. One "Pitch" is defined as the maximum daily job content that can be done by a composed crew of workers within a certain location. LBMS considers that the project is broken down to physical location, to which different activities can be assigned. The construction production is defined according to TS methodology, which offers the possibility to granulate information and measure construction performance and process at different levels (tiers). To plan and schedule the construction production according to LBMS and TS, site manager creates workflows (a sequence of activities that are needed to complete a task) for a specific location and assign crews/workers to those activities. Workflows refer to tier 3. The workflow is attached to a task (tier 2) that has to be performed in a given period. Once scheduling is done, the monitoring of activities of running task can start. Monitoring is done by foreman on a daily basis by reporting the percentage or absolute value of completed activities (input data). If a daily goal has not been met, the remained work content will be considered during the following days. Through the daily monitoring of activities, the collected input data are used for calculations of construction performance and progress KPIs, which are afterwards displayed on $3 \mathrm{D}$ model in AR. The monitoring at the lowest measureable level (activities-tier 3) is applied, because it allows the projection and aggregation of information to deliver the overall process status on superior tiers.

\section{Performance and progress indicators}

Construction industry does not have standardized measurement of performance indicators. Indicators should be in line with business goals and conform to company benchmark. The construction project is considered successful, if reaches desirable performance in terms of cost (within the budget), safety (accident free project), schedule (on-time project) and quality (conformance with specifications and standards) (Forbes \& Ahmed, 2011).

In the AR4C project, KPIs focus on areas of productivity, project schedule, quality and costs. 
Table 1 summarizes main KPIs considered. The definition of each KPIs refers to the activity level (tier 3). The most of these KPIs are reported to superior tiers by doing data aggregation from lower tiers.

Table 1: KPIs considered in the AR4C application

\begin{tabular}{|c|c|}
\hline KPIs & Definition \\
\hline $\begin{array}{l}\text { Current } \\
\text { Progress - } \\
\text { CP }\end{array}$ & $\begin{array}{l}\text { CP [\%] is a relation of the pitch } \\
\text { content of a single activity to the } \\
\text { overall pitch content of the whole } \\
\text { workflow. }\end{array}$ \\
\hline $\begin{array}{l}\text { Performance } \\
\text { Ability Ratio } \\
\text { - PAR }\end{array}$ & $\begin{array}{l}\text { PAR-value [-] is the ratio of the } \\
\text { defined content of } 1 \text { Pitch to the actual } \\
\text { measured progress on-site. Value }>1 \\
\text { indicates a lack of performance with } \\
\text { respect to the expected performance. } \\
\text { Value }=1 \text { means that the foreseen goal } \\
\text { has been met. Value }<1 \text { refers to a } \\
\text { more powerful performance than } \\
\text { expected. Ranking activities regarding } \\
\text { this criterion provides perception } \\
\text { towards improvement potentials of } \\
\text { single activities. }\end{array}$ \\
\hline $\begin{array}{l}\text { Reason for } \\
\text { non- } \\
\text { completion - } \\
\text { RNC }\end{array}$ & $\begin{array}{l}\text { RNC [-] states a root cause for non- } \\
\text { completed activities on time. It allows } \\
\text { the analysis of poorly running task. }\end{array}$ \\
\hline $\begin{array}{l}\text { Percent Plan } \\
\text { Completed - } \\
\text { PPC }\end{array}$ & $\begin{array}{l}\text { PPC [\%] is the ratio of fulfilled } \\
\text { assignments (achieved goals) to the } \\
\text { total number of assignments } \\
\text { scheduled for a particular day. If the } \\
\text { goal is achieved PPC value is } 100 \% \text {, } \\
\text { if not it is } 0 \% \text {. The PPC-value } \\
\text { provides information regarding the } \\
\text { reliability of the scheduling and the } \\
\text { smoothness of the workflow. }\end{array}$ \\
\hline $\begin{array}{l}\text { Delay } \\
\text { Indicator - } \\
\text { DI }\end{array}$ & $\begin{array}{l}\text { DI [days] is a difference between } \\
\text { planned working days and remaining } \\
\text { days (calculated only for tier } 3 \text { ) }\end{array}$ \\
\hline $\begin{array}{l}\text { Extra Effort } \\
-E E\end{array}$ & $\begin{array}{l}\text { EE [days] is a sum of Delay Indicator } \\
\text { of each activity in a task or tasks of a } \\
\text { work package (calculated only for tier } \\
0-2 \text { ) }\end{array}$ \\
\hline $\begin{array}{l}\text { Quality gate } \\
\text { - QG }\end{array}$ & $\begin{array}{l}\text { QG [-] is a number of fulfilled quality } \\
\text { checklists out of total number of } \\
\text { checks assigned to a tasks }\end{array}$ \\
\hline $\begin{array}{l}\text { Construction } \\
\text { errors - CE }\end{array}$ & $\begin{array}{l}\text { CE [-] is a number of construction } \\
\text { errors detected during inspections by } \\
\text { site manager }\end{array}$ \\
\hline $\begin{array}{l}\text { Extra costs - } \\
\text { EC }\end{array}$ & $\begin{array}{l}\text { EC }[€] \text { is an additional cost calculated } \\
\text { as a multiplication of extra effort } \\
\text { expressed in days per cost rates for } \\
\text { men-hours in terms of labor costs. }\end{array}$ \\
\hline
\end{tabular}

\section{Augmented Reality (AR)}

AR is a technology that overlays on a real world environment a computer-generated content like images, videos, animations, text, etc. In the construction industry, AR is recognized as a promising technology to improve monitoring of construction works and project communication. It is possible to show as-planned and as-built project and visualize the construction progress (Zollmann, 2014). In addition, AR can facilitate the understanding of project documentation, construction progress through 3D visualization of models on site (Meža et al., 2015). In the AR4C application, AR technology enables users to interact with $3 \mathrm{D}$ building model and embedded information in the model. Moreover, it displays in AR progress of construction task according to user's location by coloring elements of the 3D model that are superimposed on the real world. So, the deviation from the master schedule can be easily detected. Moreover, this AR visualization will be accompanied by performance and progress KPIs.

\section{Dashboard}

Dashboard is a visual interface to report most significant information at a glance through KPIs that are relevant to meet predefined objectives of the project. Dashboard helps keeping the project within the schedule and budget. It also reduces labor effort put in manual intensive reporting process. In this research project, aforementioned methodologies has been implemented and tested in a dashboard, which was developed as a web based application during the European project - ACCEPT, funded within the Horizon 2020 Framework Program. In the AR4C application, it is planned to integrate a dashboard view in order to provide users with the possibility to choose information at different levels of the project and not only focus on KPIs at task level.

\section{AR4C and Dashboard prototype}

The AR4C application is under development and currently has reached the maturity at the level 4 according to TRL scale (Technology Readiness Level). The dashboard is a prototype with TRL4 as well. It means that the main contribution was done in design, development and lab testing of single components and processes of both applications.

\section{System Architecture}

To create the AR4C prototype, Unity was chosen as a main development environment. The application is composed of several components such as: a) 3D model Management; b) Data Management; and c) GUI Management. It is necessary to import external assets to component a) and b) like 3D BIM model using .fbx file and its metadata via .xml file, respectively. Component c) allows the visualization of 3D model in $\mathrm{AR}$ and related information within the Graphical User Interface (GUI). External APIs are integrated with 
Unity: a) Tango SDK, which provides different features to gather information on the device position and orientation and to interact with it; b) Firebase SDK, which stores digital assets like, images, video, checklist, drawings and allows the AR4C application to access them whenever needed. It acts as a centralized database of the application. Scheduling data are prepared in an external software - Ms Project according to LBMS requirements and are imported to the Unity via xml. file. Master schedule contains the same WBS and LBS codes as in BIM model, task and work packages names as well as benchmark project data (e.g. durations).

Regarding the dashboard, it is an interactive web based-platform, which provides users with KPIs referred to a specific location of the construction project. The Dashboard home page is divided into 3 sections: a) 3D BIM Viewer of the current project status (Figure 2); b) panel for displaying the information relevant to the selected level (tier) of the project (Figure 3), and c) graphs to illustrate trends of several KPIs (Figure 4). Currently it is out-standing application and it has not been integrated in AR4C yet. Dashboard is a tool, which is fed with data collected form the construction site. Data are actually collected using Excel sheet and are imported manually to the dashboard.

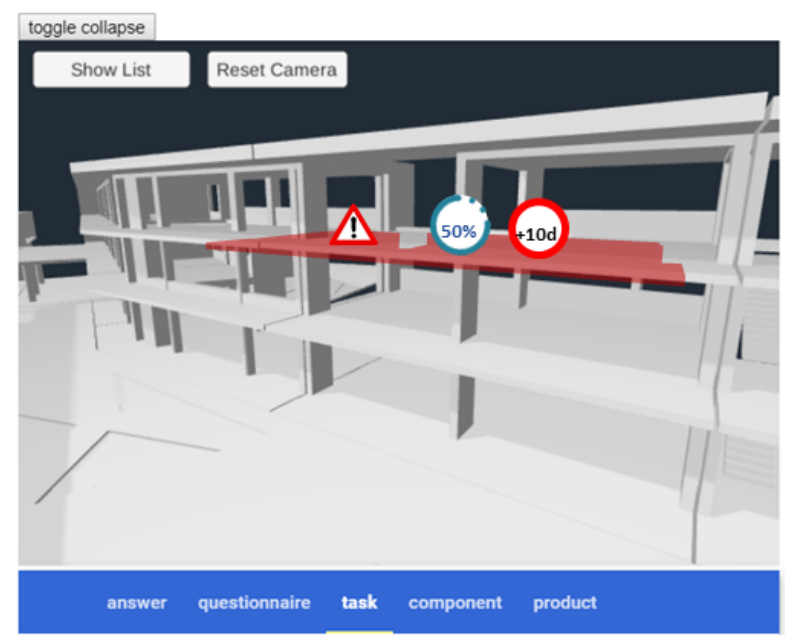

Figure 2 3D Viewer in the Dashboard.
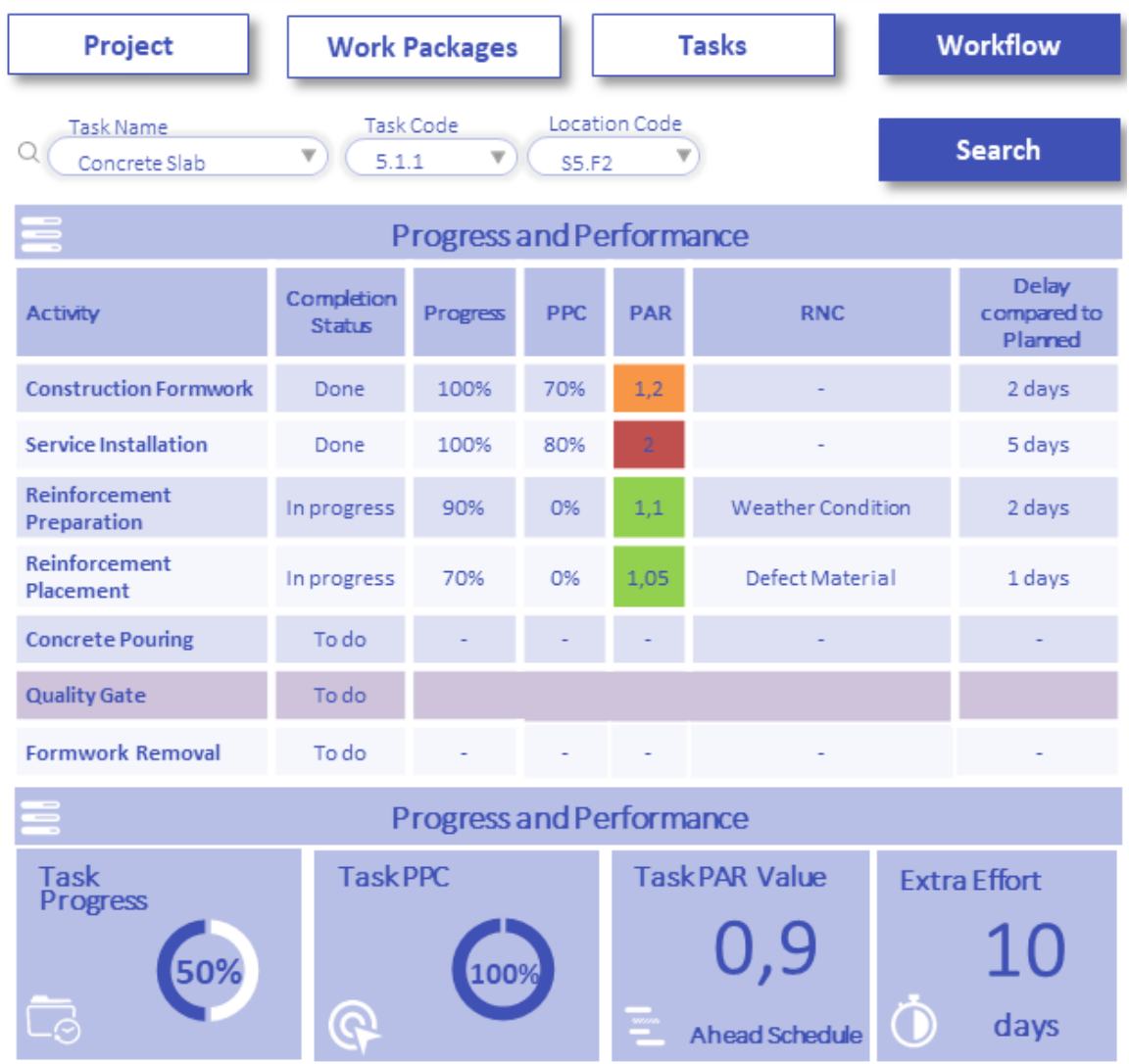

Figure 3 Information panel with construction progress and performance data for the workflow level. 


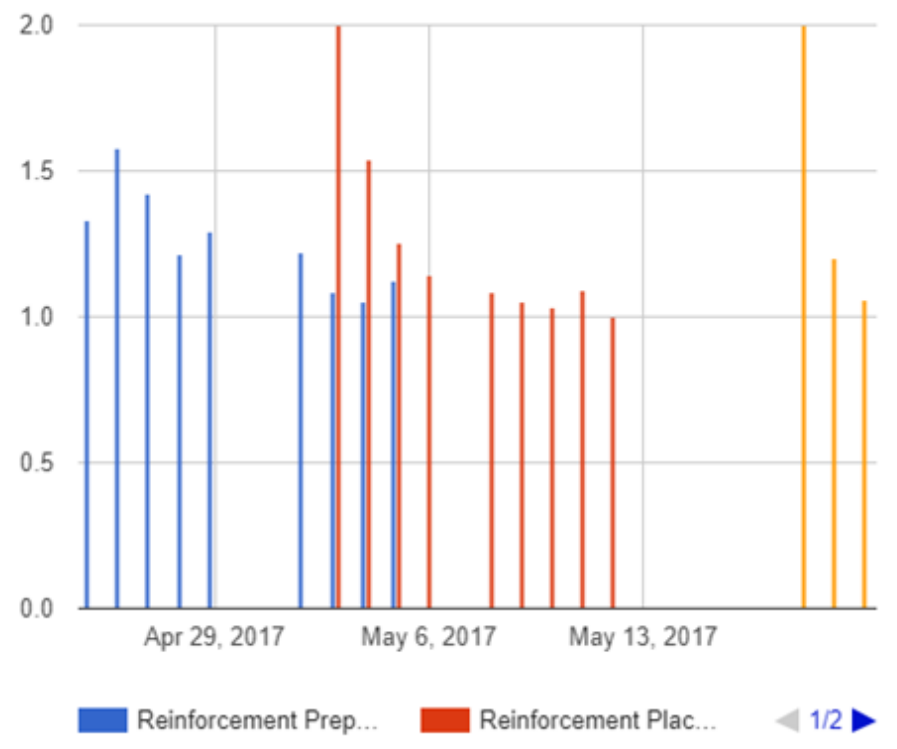

Figure 4 Graphical representation of PAR value trend.

\section{Functionalities}

Table 2 lists functionalities that have been implemented in the AR4C application so far. More information on implemented functionalities can be also found in Ratajczak et al. (2018).

Table 2: Implemented functionalities in AR4C

\begin{tabular}{|l|l|}
\hline Functionality & Description \\
\hline $\begin{array}{l}\text { Navigate 3D } \\
\text { Model }\end{array}$ & $\begin{array}{l}\text { The user navigates the 3D model } \\
\text { in the application by walking in } \\
\text { the real environment (Figure 5) }\end{array}$ \\
\hline $\begin{array}{l}\text { Visualize } \\
\text { Element } \\
\text { Information }\end{array}$ & $\begin{array}{l}\text { The user can touch every element } \\
\text { in the 3D model, and extract } \\
\text { information from it (Figure 6). }\end{array}$ \\
\hline $\begin{array}{l}\text { Read } \\
\text { Geometry } \\
\text { Information }\end{array}$ & $\begin{array}{l}\text { The user can visualize technical } \\
\text { data of a given component. }\end{array}$ \\
\hline $\begin{array}{l}\text { Filter 3D } \\
\text { Model }\end{array}$ & $\begin{array}{l}\text { The user can enable and disable } \\
\text { different layers of the 3D model } \\
\text { (Figure 5). }\end{array}$ \\
\hline $\begin{array}{l}\text { Consult Task } \\
\text { List }\end{array}$ & $\begin{array}{l}\text { The user can consult a list of tasks } \\
\text { currently available. }\end{array}$ \\
\hline $\begin{array}{l}\text { Upload/Read } \\
\text { Note }\end{array}$ & $\begin{array}{l}\text { The user can: } \\
\text { type/read a note related to a } \\
\text { selected component } \\
\text { upload/download the note } \\
\text { to/from the shared database by } \\
\text { touching a button. }\end{array}$ \\
\hline
\end{tabular}

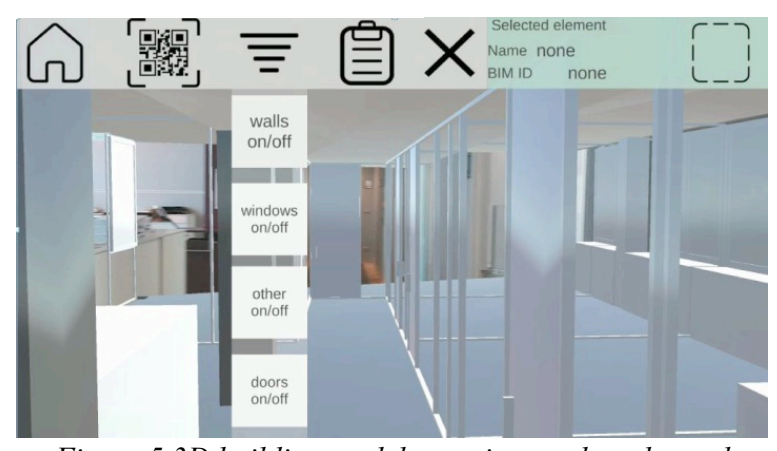

Figure 53 building model superimposed on the real world that can be filtered by layers

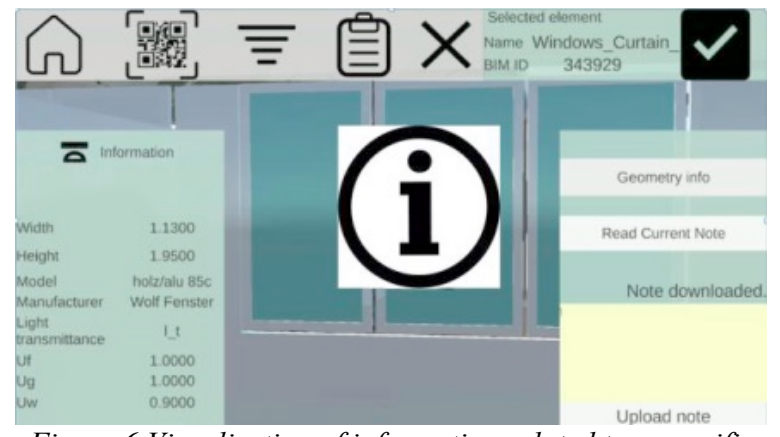

Figure 6 Visualization of information related to a specific BIM object.

\section{Preliminary testing}

The AR4C application was tested in two buildings in the area of approximately $200 \mathrm{~m}^{2}$, focusing mainly on the calibration of the 3D model alignment on the real building (Figure 7). It was important to verify if the motion tracking technology used by the application can be accurate and precise enough to use it on a construction site. After several tests it emerged that the position of the 3D building model displayed in $\mathrm{AR}$ was not always perfectly superimposed on the real 
building. The difference was variable and approximately varied between 0,4 and 1 meters. This test provided indications to improve the accuracy of the visualization of the $3 \mathrm{D}$ building model in AR. In these testing users were involved to provide their feedback on the usability of the application. It was done through focus groups, where users could use the application and fill out a questionnaire. Almost all respondents considered that it is very likely that the information provided by the AR4C prototype will allow a faster access to relevant information on site and will improve the productivity of the construction process, if the monitoring of construction works will be implemented.

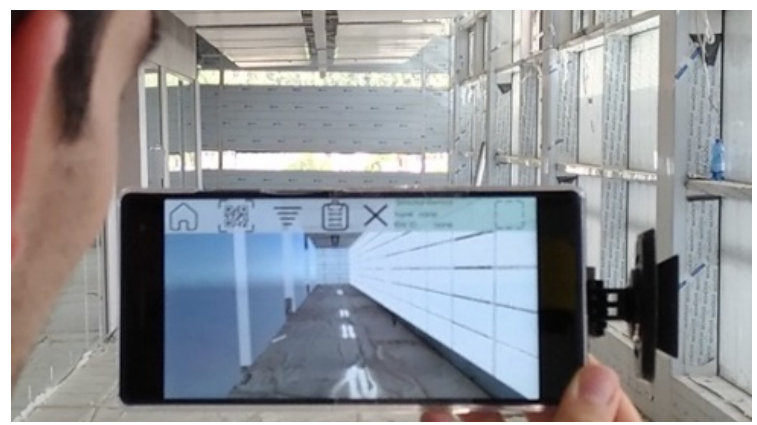

Figure 5 Test of $3 D$ model alignment on the real building.

\section{Further research}

\section{System integration}

The AR4C application requires further integration. To visualize data as it is currently done in 3D BIM Viewer in the dashboard and to enhance the project controlling by site manager during the inspection, it is necessary to develop components, which read construction progress and process KPIs for running construction tasks and correlate them with elements of the 3D model by means of WBS and LBS codes. Users should be able to access data in AR4C and see the construction performance and progress of tasks in their current location. These data should be displayed in AR by highlighting building components in different colors (red - behind schedule, green - on time, blue ahead schedule) with KPIs values. To each KPIs a color bullets are also displayed to approximatively indicate a criticality level for detected deviations that can have an impact on the overall project performance (green= no impact on the project; yellow = deviations are tolerable and do not impact on the project); orange $=$ heightened criticality of the project performance), red $=$ very critical to the project). A mock-up of this implementation is shown in Figure 8.

Another planned aspect in this research is the integration of the automatic recognition of locations in the construction site according to LBS codes. It is required to provide information on scheduled tasks, checklist, progress and performance KPIs, while site manager is walking through the construction site.
For that reason, the use of Bluetooth low energy beacons will be investigated in order to offer contextualized information. By applying beacons and naming them with LBS codes, the AR4C will be able to recognize, which beacon is approaching and in consequence will display scheduled task as well as visualize information on task progress and performance. Schweigkofler et al. (2018) have in part investigated this approach.

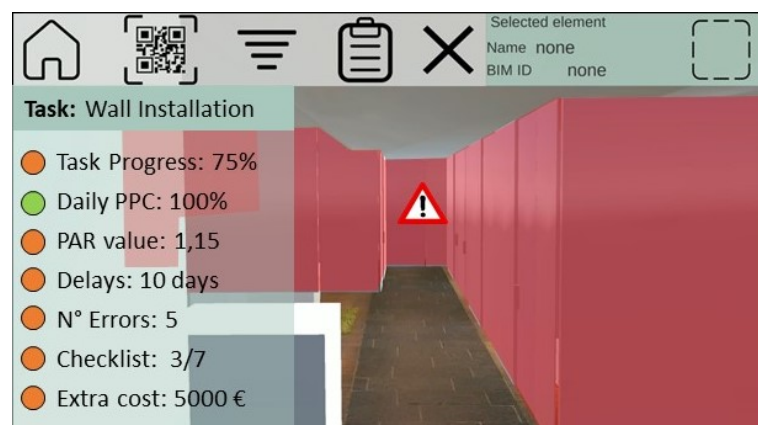

Figure 8 Visualization of construction progress in AR with performance KPIs for a specific task

\section{Validation}

As further activities in the AR4C project, it is planned to conduct testing in a construction site to evaluate benefits and obstacles that can be generated by introducing the AR4C application in real world environment. It will be important to determine, if the proposed monitoring method can improve the project control and anticipate corrective decisions. In addition, it will be attempt to evaluate how this method can improve the productivity of the construction process. Since the research project is performed in the collaboration with the construction company Budimex in Poland, the application will be tested in one of its construction projects. The user acceptance and experience will be also fundamental during the validation phase. For this reason, people from the construction site will be asked to evaluate the AR4C application by using it in predefined scenarios, which will simulate a real situation on site. Beyond the enduser test, the authors will focus also on: a) defining with site manager KPIs that are relevant for Budimex, b) defining benchmark and ranges for these KPIs, c) and measuring KPIs.

\section{Conclusion}

This paper describes methodologies, technologies as well as implemented and planned functionalities in a mobile AR application for the construction site, socalled AR4C, which runs on the Android smartphone - Lenovo Phab 2 Pro. It provides users with contextaware information related to the construction project like 3D model, technical features of building components and materials, list of construction tasks, installation procedures as well as quality and 
construction checklists. The application integrates lean construction techniques like Location-based Management System (LBMS) with Building Information Modeling (BIM) in order to support the efficient management of construction works on site. So far, preliminary tests of AR4C were carried out in two buildings at Fraunhofer Italia. A group of specialists tested the application and provided a good feedback regarding the usability and utility of the application on the construction site. They agreed that the AR4C application could improve the communication by providing a faster access to relevant information on site. It is also likely that it will improve building quality by avoiding construction error and will enhance the productivity of construction processes, when the monitoring of construction works will be implemented. For this reason, the authors plan to implement new features related to the controlling process of construction works through performance and progress KPIs displayed in AR and dashboard view. As a further step, the testing of all methodologies and technologies implemented in AR4C will be carried out on a real construction site.

\section{Acknowledgments}

The authors would like to thank Andrei Popescu for IT development of the AR4C, from his thesis: "ContextAware Information Delivery for the Construction Site Using a Mixed Reality Mobile Application". The authors gratefully acknowledge the contributions of the other partners from the ACCEPT project, especially Peter Leo Merz from TIE Germany, Vincent Delfosse, Hatem Bejar, Anabelle Rahhal, Pierre Leclercq from LUCID Lab, Jason Page and Edward Gooden from Ingleton Wood.

\section{References}

Andersson, N., \& Christensen, K. (2007) Practical Implications of Location-based Scheduling. In: CME25: Construction Management and Economics: past, present and future, Taylor and Francis Group.

BIM360 Docs (2019) Autodesk (https://www.autodesk.com/bim-

360/platform/construction-document-managementsoftware/).

BIM360 Plan (2019) Autodesk (https://www.autodesk.com/bim-360/platform/bim360-plan/).

BIMsight (2015) Tekla (https://www.tekla.com/teklabimsight/).

Connected BIM (2019) Oracle Aconex

(https://help.aconex.com/aconex/our-main-

application/aconex-release-notes-

updates/introducing-connected-bim-expanded-

aconex-mobile-suite-improved-process-

management).
Dallasega, P., Matt, D.T. \& Krause, D. (2013) Design of the Building Execution Process in SME Construction Networks. In: Proceedings of the 2nd International Workshop on Design in Civil and Environmental Engineering, pp. 7-15, Thompson K. editor, Worcester, UK.

Dehlin S. \& Olofsson T. (2008) An evaluation model for ICT investments in construction projects, In: ITcon, Vol. 13, Special issue Case studies of BIM use, pp. 343-361.

Eastman, C. M., Teicholz, P., Sacks, R., \& Liston, K. (2008) BIM handbook: A guide to building information modeling for owners, managers, architects, engineers, contractors, and fabricators, Wiley, Hoboken, N.J.

Golparvar-Fard, M., Peña-Mora, F., \& Savarese, S. (2009) D4AR - A 4-dimensional augmented reality model for automating construction progress monitoring data collection, processing and communication. In: Journal of Information Technology in Construction, Vol. 14, pp. 129-153.

IBC (2000) Industry Benchmarking Consortium: Project Control Best Practice Study by IPA Independent Project Analysis.

IBC (1999) Industry Benchmarking Consortium: Cost Engineering Committee (CEC).

Kenley, R., \& Seppänen, O. (2010) Location-based Management System for Construction: Planning, Scheduling and Control. Spon Press, London and New York.

KPMG international (2015) Global construction survey 2015: Climbing the curve. https://assets.kpmg/content/dam/kpmg/pdf/2015/04/gl obal-construction-survey-2015.pdf [Retrieved on February 2019].

Kopsida, M. \& Brilakis I. (2016) Markerless BIM Registration Methods for Mobile Augmented RealityBased Inspection. In: Proceedings of the 11th European Conference on Product and Process Modelling (ECPPM 2016), Limassol, Cyprus, 7-9 September.

Lamptey W.N. L. \& Fayek A.R. (2012) Developing a Project Status Dashboard for Construction Project Progress Reporting. In: International Journal of Architecture, Engineering and Construction, 1(2), pp. 112-120.

Latista (2015) Oracle (https://www.microsoft.com/enus/p/oracle-latista-field-

management/9nblggh2spn8?activetab=pivot:overvie $\underline{\text { wtab)}}$.

Lee, S. \& Pena-Mora, F. (2006) Visualization of Construction Progress Monitoring. In: Joint International Conference on Computing and Decision 
Making in Civil and Building Engineering, Montreal, Canada, 14-16 June 2006, pp. 2527-2533.

McKinsey Global Institute (June 2016) Digital Europe: Pushing the frontier, capturing the benefits, McKinsey \& Company 2016.

Maalek, R. \& Sadeghpour, F. (2012) Reliability assessment of Ultra-Wide Band for indoor tracking of static resources on construction sites, CSCE, Edmonton.

Memon, A. H., Rahman, I. A., Aziz, A.A.A. (2012) The cause factors of large project's cost overrun: a survey in the southern part of peninsular Malaysia. In: International Journal of Real Estate Studies, 7(2).

Mills, A., Love, P.E. \& Williams P. (2009) Defect costs in residential construction, In: J. Constr. Eng. Manag., 135 (1), pp. 12-16.

Meža, S., Turk, Ž., \& Dolenc, M. (2015) Measuring the potential of augmented reality in civil engineering. In: Advances in Engineering Software, 90, pp. 1-10.

Olawale, Y. \& Sun, M. (2010) Cost and time control of construction projects: Inhibiting factors and mitigating measures in practice. In: Construction Management and Economics. 28 (5), pp. 509-526.

Nassar, N. K. (2009) An integrated framework for evaluation of performance of construction projects. In: PMI® Global Congress 2009-North America, Orlando, FL. Newtown Square, PA: Project Management Institute.

Navon, R. (2007) Research in automated measurement of project performance indicators. In: Automation in Construction, 16(2), pp. 176-188.

Roh, S., Peña-Mora, F., Fard, M. G., \& Han, S. (2009) Visualization Application for Interior Progress Monitoring in 3D Environment. In: Construction Research Congress 2009, Seattle, Washington, USA, April 5-7, pp. 51-60, ASCE.

Ratajczak, J. et al. (2017) Digital Tools for the Construction Site. A Case Study: ACCEPT Project. In: LC32017: Volume I - Proceedings of the Joint Conference on Computing in Construction (JC3), Heraklion, Greece, pp. 981-988.

Ratajczak, J., Schweigkofler, A., Riedl, M. \& Matt, D.T. (2018) Augmented Reality Combined with Location-Based Management System to Improve the Construction Process, Quality Control and Information Flow. In: Proceedings of the 35th CIB W78 2018 Conference: IT in Design, Construction, and Management, October 1-3, 2018, Chicago, Illinois, USA.

Sacks, R., Barak, R, Belaciano, B., Gurevich, U. \& Pikas, E. (2013) KanBIM Workflow Management System: Prototype implementation and field testing.
In: Lean Construction Journal, pp. 19-35.

Sacks, R., Koskela, L., Dave, B.A. \& Owen, R. (2010) Interaction of Lean and Building Information Modeling in Construction. In: Journal of Construction Engineering and Management, September 2010, Vol.136(9), pp. 968-980.

Schweigkofler, A., Pasetti Monizza, G., Domi, E., Popescu, A., Ratajczak, J., Marcher, C., Riedl, M., \& Matt, D. (2018) Development of a digital platform based on the integration of augmented reality and BIM for the management of information in construction processes. In: Proceedings of the IFIP 15th International Conference on Product Lifecycle Management. Special session 1.4 - Building Information Modeling, July 1-4, Turin, Italy.

Seppänen, O. (2009) Empirical research on the success of production control in building construction projects. (Doctoral thesis), Department of Structural Engineering and Building Technology, Faculty of Engineering and Architecture, Helsinki University of Technology, Espoo, Finland.

Seppänen, O., Evinger, J. \& Mouflard, C. (2014) Effects of the location-based management system on production rates and productivity. In: Construction Management and Economics, 32(6), pp. 608-624.

The Economist (2000) Construction and the Internet, published on January 15.

TwinBIM (2017) Dalux
(https://www.dalux.com/dalux-field/twinbim/).

Vico Office (2012) Trimble

(https://connect.trimble.com/feature/vicooffice.html).

VisiLean Software (2019) VisiLean (http://visilean.com/).

Yates, J. K. \& Epstein, A. (2006) Avoiding and minimizing construction delay claim disputes in relational contracting. In: Journal of Professional Issues in Engineering Education and Practice, 132(2), pp. 168-179.

Yi, W. \& Chan, A.P.C. (2014) Critical Review of Labor Productivity Research in Construction Journals. In: Journal of Management in Engineering, (April), pp. 214-225.

Zavadskas, E.K., Vilutienè, T., Turskis, Z., \& Šaparauskas, J. (2014) Multi-criteria analysis of Projects' performance in construction. In: Archives of Civil and Mechanical Engineering, 14(1), pp. 114121.

Zollmann, S., Hoppe, C., Kluckner, S., Poglitsch, C., Bischof, H., \& Reitmayr, G. (2014) Augmented reality for construction site monitoring and documentation. In: Proceedings of the IEEE, 102(2), pp. 137-154. 